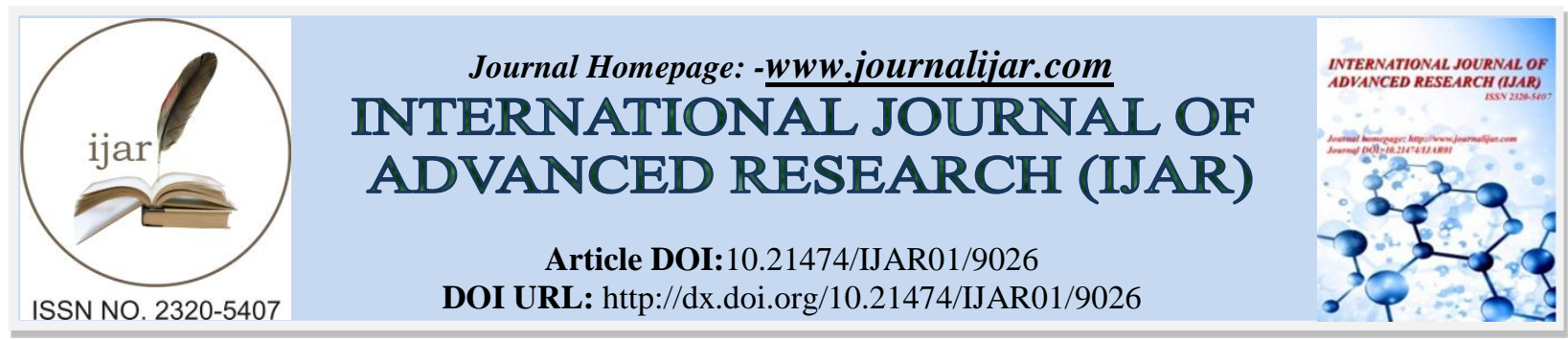

RESEARCH ARTICLE

\title{
DESIGN, IMPLIMENTATION AND FABRICATION OF PERMANENT MAGNET SYNCHRONOUS GENERATOR.
}

Yash R. Khakhi .

Electrical Engineering Department,Gandhinagar Institute of Technology, Gandhinagar.

\section{Manuscript Info}

\section{Manuscript History}

Received: 04 March 2019

Final Accepted: 06 April 2019

Published: May 2019

Key words: -

Material, Nylon -6, Permanent magnets, Copper, Electromagnetic analysis, PMSM (permanent magnet synchronous machine), magnetic material, system simulation, manufacturing process.

\begin{abstract}
This paper presents a study on material selection basis on characteristics, model designing calculation and designed model analysis using 2-dimensional (2D) analysis of magnetostatic analysis and its fabrication process for the permanent magnets machine. Conventional machines are having higher reactance losses in windings and difficult manufacturing process because of its design. Proposed design of machine is fully based on conventional stator and rotor geometry consisting permanent magnets and special type of winding to lower the reactance losses. Machine is fully fabricated locally and tested.
\end{abstract}

Copy Right, IJAR, 2019,. All rights reserved.

\section{Introduction:-}

The PMSM (Permanent Magnet Synchronous Machine) is widespread for the power generation application at various power generators because of its higher value of ratio of power and mass, higher efficiency, reduced size and most importantly the lower maintenance operation. But the major drawback of these machines are the higher costing of the permanent magnets, winding losses and demagnetizing tendency of permanent magnets due to some abnormal working conditions of the machine [2]. Thus, the purposed model of the machine should be such that to have proper dimensions of permanent magnets accompanied with overall reduction in machines main dimensions and weight of the machine which makes is portable. The design must take care of demagnetizing effect of permanent magnet affected by flow of armature current. Hence, the proposed design considers that the machine can be driven by external prime mover having appropriate control which can deliver power from model to the grid. It is to be noted that this research and development work is fully self-funded with aiming of developing a unique approach for permanent magnet-based machine drives. This type of machine is not readily available in Indian market. Adding the problem of availability of high energy density permanent magnets in the local market. Presently all the magnets were made available from the foreign sources.

\section{Material Selection}

Material selection is one of the major factors while designing a rotating electrical machine. Elimination of unnecessary losses can be reduced by proper selection of material. In the function of energy conservation material plays an important role as all the calculations of designing is done on the basis of properties of material selected. Aiming towards higher power density currently PMSM deal with a higher flux in the airgap and resulting in higher flux densities in stator and rotor parts.

Conventional machines have stator and rotor made up of iron material which is having influence on iron losses in the machine. As any metallic part of the machine have greater or lesser contribution in iron loss of the machine. By 
proper selection of other material having same qualities can make loss calculation smaller for the machine. Selection of nylon 6 polymer material is the key feature of the design [1]. Nylon 6 material has all the required mechanical properties such as high mechanical stability and temperature resistance characteristics as well as good insulating property along with good wear resistance. This feature cannot completely replace the iron material that are being used in conventional machines but most of the requirements can be fulfilled by this material.

Selection of magnet for the production of great amount of flux which is essential for the higher flux density machine is the most crucial part. Various types of magnets are available in the market ranging from industry made magnets to the rare earth magnets which are the strongest magnets among all other types. By means of strongest magnets it is assumed that the generation of magnetizing field is at its extreme level. Rare earth magnets made up from the alloys of the rare earth material offer the best magnetization property especially the neodymium (NdFeB) magnets. Tale 1 shows the different magnetic properties offered by different magnets.

\begin{tabular}{|c|c|c|}
\hline Magnet & Remanence (T) & $\begin{array}{c}\text { Coercivity } \\
(\mathrm{kA} / \mathrm{m})\end{array}$ \\
\hline Alnico & 0.6 & 0.07 \\
\hline MnBi & 0.48 & 0.37 \\
\hline SmCo & 0.83 & 1.0 \\
\hline Neodymium & 1.2 & 1.2 \\
\hline
\end{tabular}

Table 1: -Magnetic properties of different material

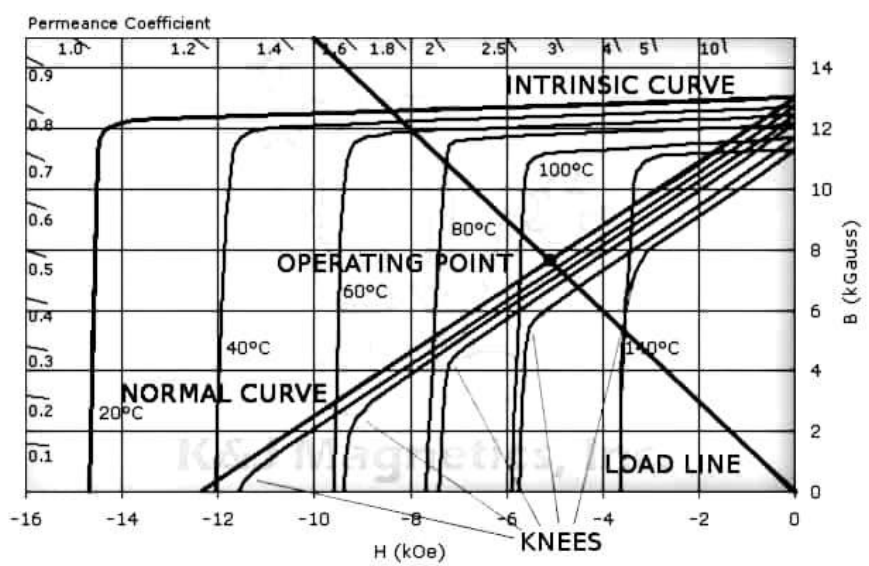

Fig 1: -B-H characteristic of Neodymium

B-H characteristics graph revels the $1^{\text {st }}$ quadrant operation of hysteresis loop for neodymium magnets at different working temperature range dependent upon the load characteristics. As shown in figure 1 neodymium magnets offer best retentivity(B) and coercivity (C) over wide temperature range and can operate between $20^{\circ} \mathrm{C}$ to $140^{\circ} \mathrm{C}$. hence, due their higher temperature resistivity they can be used in the machine with proper dimensions and grade of magnet.

\section{Design of the proposed model Structural information}

Proposed design of the machine is closed drum type structure made from nylon 6 material. Stator of the machine is having 21 slots and rotor is having 12 skewed slots for magnets. There will be a special type of winding to cut the change of magnetic field of magnets. Other mechanical supporters like supporting members, bearings, conductor covers are also a part of structural design of the machine.

\section{Selection criteria}

Stator and rotor type geometry is used to boost the utilization of permanent magnets. Selecting higher number of poles is beneficial as it gives smaller length of magnetic circuit, supporting the smaller airgap, lower synchronous speed of the machine and it supports the smaller size of machine. 


\section{Calculation of main dimensions}

Calculation of machine's main dimensions is based upon the PMSM dimensions calculation method [2].

$$
\mathrm{KVA}=11 \times \mathrm{K}_{\mathrm{w}} \times \mathrm{B}_{\mathrm{av}} \times \mathrm{ac} \times \mathrm{D}^{2} \times \mathrm{L} \times \mathrm{n}_{\mathrm{s}} \times 10^{-3}
$$

$\mathrm{K}_{\mathrm{W}}$ and $\mathrm{B}_{\mathrm{av}}$ are the stator winding factor and average flux density of the machine respectively. Value of $\mathrm{Kw}$ is ranged between 0.85 to 0.95 and range of $\mathrm{B}_{\mathrm{av}}$ is between 0.45 to 0.8 . by proper consideration of the value of $\mathrm{K}_{\mathrm{w}}$ and $\mathrm{B}_{\mathrm{av}}$ for 12 pole machine, table 2 shows the results of calculation:

\begin{tabular}{|c|c|}
\hline Stator Outer Diameter & $223 \mathrm{~mm}$ \\
\hline Stator inner Diameter & $83 \mathrm{~mm}$ \\
\hline Rotor Diameter & $69 \mathrm{~mm}$ \\
\hline Axial length & $192 \mathrm{~mm}$ \\
\hline Air Gap & $7 \mathrm{~mm}$ \\
\hline
\end{tabular}

Table 2:-Main dimensions of the $1 \mathrm{KW}$ PMSM

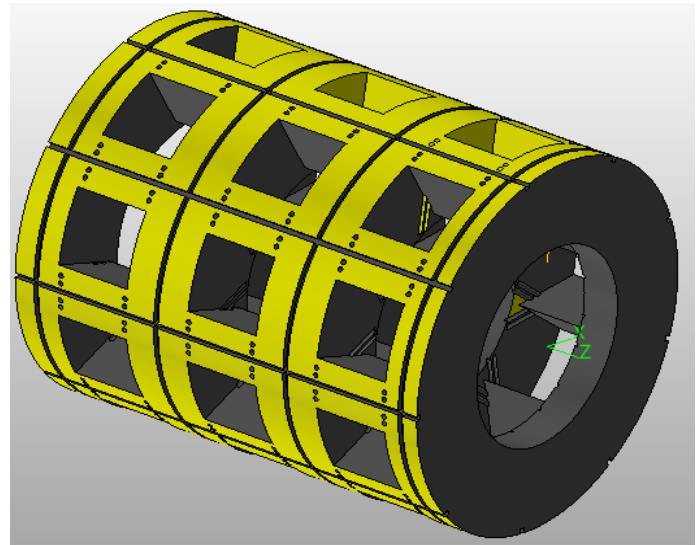

Fig 2:-Proposed stator geometry for $1 \mathrm{~kW}$ machine

Figure 2 shows the geometrical designed model of stator in which gives the clear-cut view of proposed prototype of the machine. Proposed machine consists of stator and rotor having slots for permanent magnets. The slot/pole combination of machine influences cogging torque and torque ripple characteristics in machine. Hence, generation of cogging torque [9] is one of the major problems in machines having permanent magnets and so, its elimination is more important as magnets in both stator and rotor are in opposite manner and their tendency is to attract each other which will result in opposing the smooth rotation of rotor.

\begin{tabular}{|c|c|}
\hline Number of slots $\left(\mathrm{N}_{\mathrm{s}}\right)$ & 21 \\
\hline Number of poles $\left(\mathrm{N}_{\mathrm{p}}\right)$ & 12 \\
\hline Ratio of slot/ pole & 1.75 \\
\hline Number of cogging torque in 1 slot pitch & 3 \\
$\mathrm{~N}_{\text {period }}=\frac{\mathrm{N}_{\mathrm{p}}}{\mathrm{HCF}\left\{\mathrm{N}_{\mathrm{s}}, \mathrm{N}_{\mathrm{p}}\right\}}$ & \\
\hline Optimum skew angle, & 2.85 \\
$\theta_{\text {sk }}=\frac{360}{\mathrm{~N}_{\mathrm{s}} \mathrm{N}_{\text {period }}}$ & \\
\hline
\end{tabular}

Table 3:-Skewing angle calculation

Skewing of magnets in rotor will give better results in smooth running of rotor by eliminating cogging torque [10]. Table 3 shows the calculation of skewing angle of magnets in rotor. In proposed model of the machine the rotor magnets skewing angle is 4 degree which is more than the optimum skewing angle of the machine.

\section{Hub design}

Hubs having permanent magnets and a special type of winding on its periphery to collect the generated EMF resulting from the variation of flux in the machine. Design of hub is such that which can provide mechanical 
strength to winding and magnets. Also, it must have some manufacturing and installation benefits. Stator is having 21 slots of dimension $40 \times 40 \times 40 \mathrm{~mm}$. and so, design of hub is fully dependent on the slot.

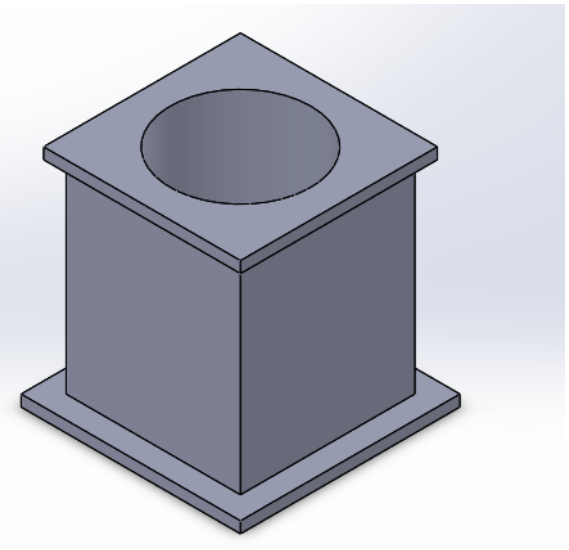

Fig 3: -Hub design

Designed hub is typically "I" shaped structure having a $25 \mathrm{~mm}$ hole at the bottom side on hub for the magnet. Benefit of "I" shaped structure is the it provides mechanical strength to winding and not allow turns to move from its place.

\section{EMF generation calculation}

Following the faraday's law for the calculation of emf generation and designing turns in the hub.

Generated emf, $\varepsilon=-\mathrm{N} \frac{\mathrm{d} \emptyset}{\mathrm{dt}}=-\mathrm{N} \frac{\Delta(\mathrm{BA})}{\Delta \mathrm{t}}$

$\mathrm{B}$ - Magnetic flux density $(\mathrm{T})$

A - Area $\left(\mathrm{m}^{2}\right)$

$\mathrm{N}-$ No. of turns

Stator is having total 21 hubs consists of turns. Each hub consists of 74 turns having flux density of $5 \times 10^{3}$ gauss. Hence each hub is able to develop an emf of $12 \mathrm{mV}$ per second. All the hubs can be connected in series or parallel manner according to requirement.

\section{Magnetostatic analysis of model}

\section{Simulation of model}

Ansys of machine with similar type of specification such as PMSM will give better idea of working of proposed proto type [3].

Here, Table 3 shows the specifications of PMSM required for the magnetostatic analysis of machine having same main dimensions as proposed model of the machine.

\begin{tabular}{|c|c|c|c|}
\hline Rated & Item & Unit & Specification \\
\hline & Current & $\mathrm{A}$ & 2.9 \\
\hline & Power & $\mathrm{kW}$ & 1 \\
\hline & Speed & $\mathrm{Rpm}$ & 1500 \\
\hline Stator & No. of Slots & - & 48 \\
\hline & O.D & $\mathrm{mm}$ & 223 \\
\hline & I.D & $\mathrm{mm}$ & 83 \\
\hline & Tooth width & $\mathrm{mm}$ & 4.3 \\
\hline Rotor & Poles & - & 4 \\
\hline & Diameter & $\mathrm{mm}$ & 69 \\
\hline & Axial length & $\mathrm{mm}$ & 192 \\
\hline
\end{tabular}

Table 4: -Analysis Specifications 
Ansys 2D geometry of $1 \mathrm{~kW}$ pmsm machine having stator, slots, rotor, Airgap and shaft is shown in figure 4 .

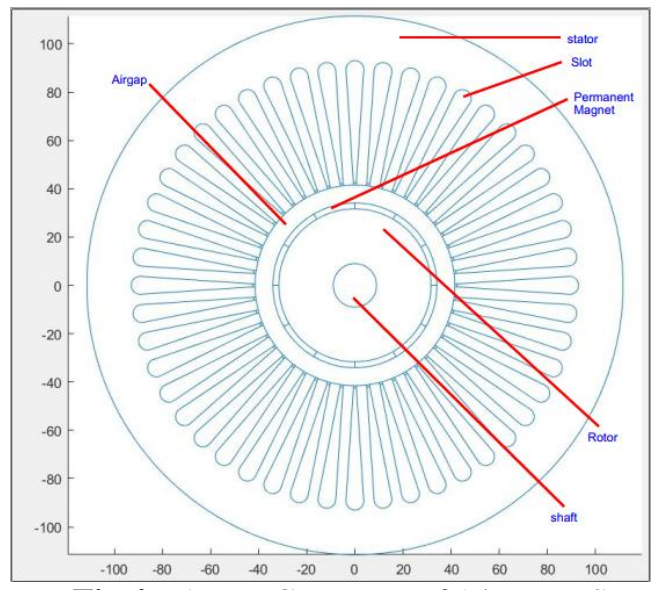

Fig 4: -Ansys Geometry of 1 kW PMSM

Distribution of magnetic flux due to the permanent magnets is shown by magnetic flux density and magnetic field intensity graph of the machine using magnetitic analysis of the machine which are shown here in figure 5 and 6.

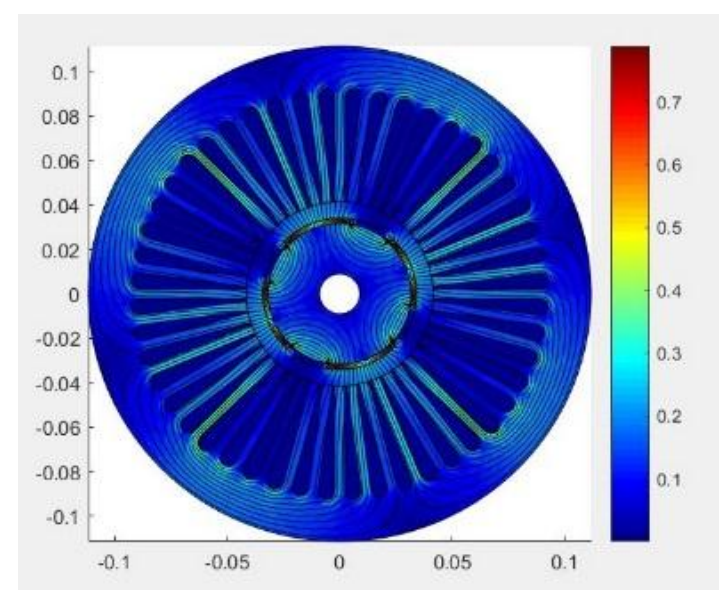

Fig 5: -Magnetic flux density

Figure 5 depicts that slots which are covered by the magnets at an instinct having higher flux density and the slots which are present between to magnets having a little bit lower magnetic density.

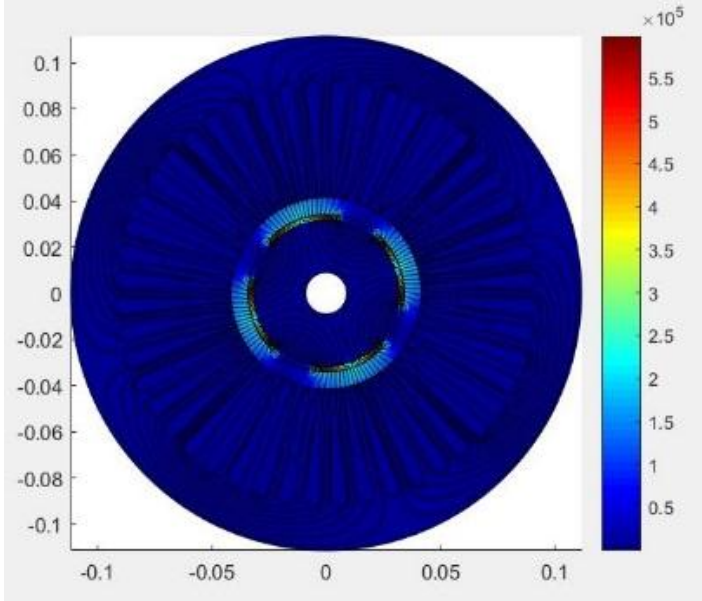

Fig 6:-Magnetic field intensity 
Figure 6 revels the information of the magnetic field intensity which is almost same throughout the structure. Airgap is having higher magnetic intensity favoring that lowest possible airgap gives higher magnetic intensity to the machine.

These graphs clearly show that use of permanent magnet of specific grade and dimensions that gives sufficient amount of magnetic field to each part of the machine stating that none of the part is heading towards saturation point while rotation of the rotor.

\section{Simulation result}

Simulation of same geometry at different advance angle keeping the other values constant gives the actual performance sense of the machine. At different advance angle machine work as either motor or generator. Simulated cases are also helpful for the study of loss in the machine.

\begin{tabular}{|c|c|c|c|}
\hline Parameter & Case 1 & Case 2 & Case 3 \\
\hline Rotor speed (RPM) & 1500 & 1500 & 1500 \\
\hline Advance angle & 60 & 120 & 360 \\
\hline Supply frequency (Hz) & 50 & 50 & 50 \\
\hline $\begin{array}{c}\text { Total torque } \\
\text { (N-m) }\end{array}$ & 0.67 & -0.13 & 0.81 \\
\hline RMS phase back-EMF (V) & 15.66 & 15.66 & 15.66 \\
\hline Input electrical power (W) & 107.134 & -21.18 & 131.55 \\
\hline Output mechanical power (W) & 106.32 & -20.72 & 127.14 \\
\hline Efficiency & $95 \%$ & $77.83 \%$ & $05.88 \%$ \\
\hline Power factor & 0.84 & 0.16 & 0.8 \\
\hline Stator winding loss (W) & 2.08 & 2.08 & 3.08 \\
\hline Total iron core loss (W) & 2.72 & 2.5 & 0.24 \\
\hline Eddy current iron core loss (W) & 0.19 & 0.17 & 3.11 \\
\hline Hysteresis iron core loss (W) & 2.53 & 2.32 & 0.004 \\
\hline Magnet eddy current loss (W) & 0.006 & 0.01 & \\
\hline
\end{tabular}

Table 5: -Simulation result

Table 5 shows the result of magnetostatic analysis at 3 different advance angles. At 60 and 360 advance angle motor rotate in clockwise direction and at 120 degree it rotates in counter clockwise direction. Rotating in counter clockwise direction machine takes mechanical power and work as a generator delivering electrical power. Focusing on the losses in the machine, results shows that the machine is having constant stator winding loss in all the cases but variation in the losses other than stator winding loss is subjected to change of advance angle in the machine. Machine is having the least winding $\mathrm{Cu}$ loss and magnetic loss because of its special type of winding configuration and use of high graded neodymium magnets.

\section{Fabrication of the proposed design}

Proposed design of the machine is fully in $\mathrm{CNC}$ and $\mathrm{VMC}$ machine. All the designing work is performed on machine designing software. Figure 7 and 8 show the designed stator, rotor [7] and hubs of the proposed model made up of nylon 6 polymer material. 


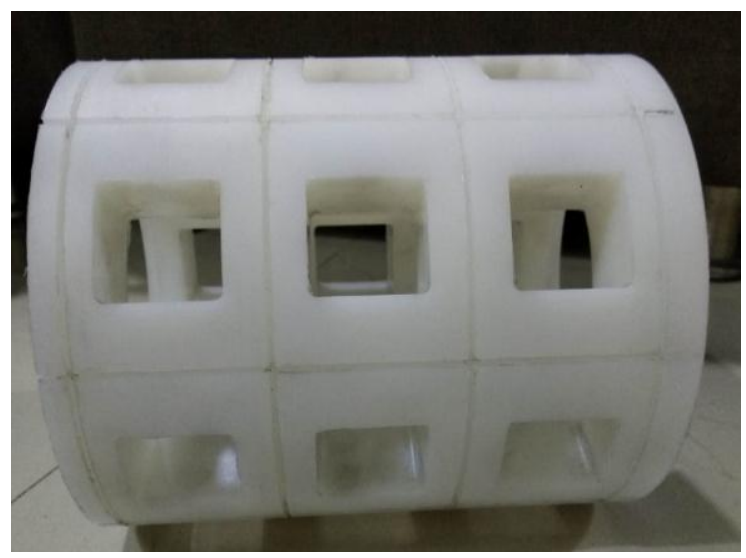

Fig 7:-Stator

Stator having slots for hubs containing winding and rotor having slots for the permanent magnets. Hubs are shown here in figure 8 having slots for permanent magnet. Final fabricated proto type of the machine is shown in figure 9 , which consist all the parts of the proposed design of the machine.

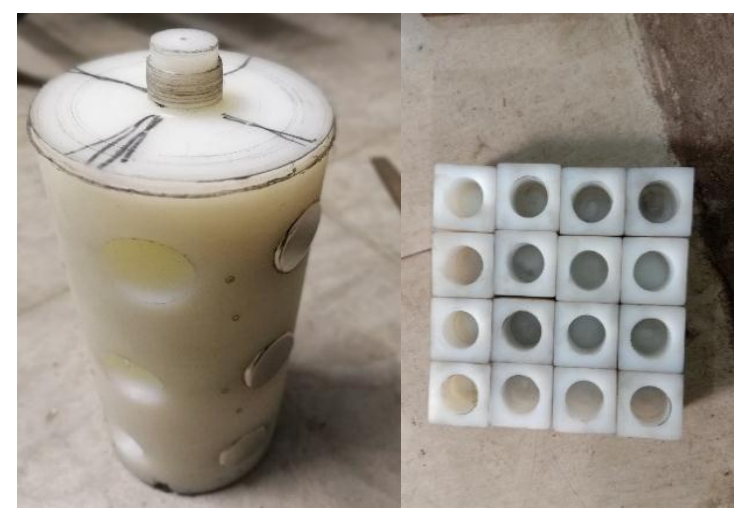

Fig 8:-Fbricated rotor and hub

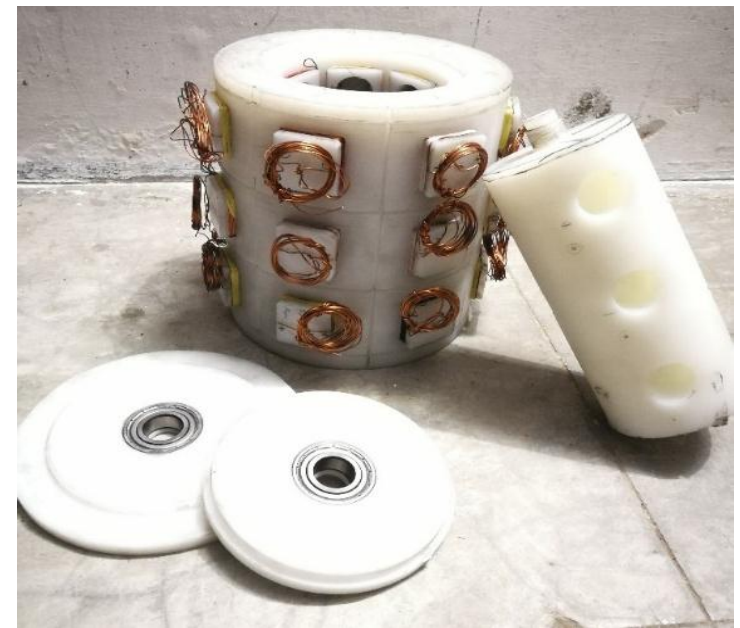

Fig 9: -Fabricated proto type

\section{winding scheme}

All the hubs in stator having winding to collect the EMF generated due to change in magnetic flux. There are many different of series and parallel combination in which these hubs can be connected. All the winding connection configuration is fully dependent on the load requirement. To get higher voltage level winding should be connected in series manner or to get higher current rating winding should be connected in parallel manner. 


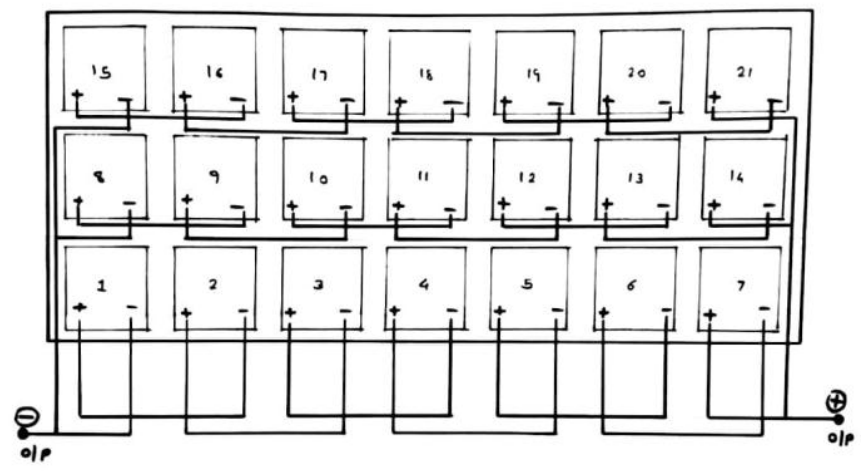

Fig 10: -winding connection scheme

Here, fig 10 shows the winding diagram of the machine. These windings are connected in series and parallel manner to get the required level of voltage and current.

Calculation of generated voltage and current,

Accoring to the connection diagram,

EMF generated by each bifilar hub $=$ E volt

Current from each bifilar hub $=\mathrm{I}$ amp.

Total induced EMF by machine

$=\mathrm{E}+\mathrm{E}+\mathrm{E}+\mathrm{E}+\mathrm{E}+\mathrm{E}+\mathrm{E}=7 \mathrm{E}$ volt

Total current $=\mathrm{I}+\mathrm{I}+\mathrm{I}=3 \mathrm{I}$ amp.

\section{Testing of the protoype}

Figure 11 shows the testing of the proto type machine, in which the fabricated machine is coupled to the 1 phase induction motor so that it can be tested over various speed range.

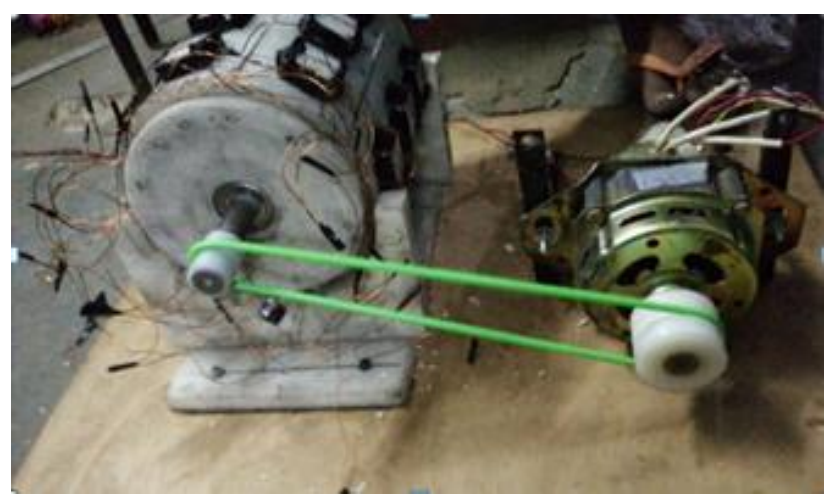

Fig 11: -Testing of fabricated machine

Machine is tested for the stated winding scheme. It is able to generate DC voltage of different level when it is subjected to variable speed through the induction motor.

\section{Testing results}

Table 6 shows the testing results of proto type machine. The machine is tested at various speed and generated emf is noted.

\begin{tabular}{|c|c|}
\hline Speed of rotor (RPM) & Generated EMF $(\mathrm{mV})$ \\
\hline 100 & 4.6 \\
\hline 200 & 10.1 \\
\hline 400 & 19.4 \\
\hline 800 & 36.7 \\
\hline
\end{tabular}




\section{0} 40.3

Table 6: -Testing results

Table 6 depicts that generation of emf is dependent on the speed of the rotor. Increase in speed will cause continuously change in magnetic field at high speed resulting into more generation of emf.

In addition, it is expected that further more emf can be fetch by changing winding scheme. However, this machine is tested with 7 coils in series with 3 parallel sets of coils.

\section{Conclusion: -}

This paper gives the detailed study on material selection, software analysis and fabrication process for the proposed design of the machine to generate DC voltages. It is proposed that nylon type polymer material can be used for the small rated machine as it is having all required qualities and can eliminate the major iron losses. High graded rare earth magnetic material can be used to achieve high power density in machine. After the positive results from the testing of proto type it can be concluded that DC voltage is generated by machine and further more improvement can be led machine towards better operation and more generation of electrical energy.

\section{Acknowledgement: -}

The author would like to acknowledge the project guide for providing their support and guidance for the ansys of the proposed model.

\section{References: -}

1. IJSR article on chemistry, properties and uses of Nylon material by parth vagholkar, September 2016 , volume 5.

2. IEEE paper on Design, Fabrication and analytical investigation of permanent magnet generator by Subhrakanti Nanda and Mainak Sengupta, 978-1-4799-6373-7/14.

3. S. Paitandi And M. Sengupta, Design, analysis of a PMSM and its comparative study With an Induction Machine of same nominal rating, NPEC, December 2013, IIT Kanpur.

4. IEEE paper on Sizing and optimization models: design of a set of two Permanent magnet generators by R. Carlson, F. Wurtz, H. Voltolini 978-1-4673-0141-1/12.

5. Bachelor's thesis on Design of a permanent magnet generator with compensated reactance winding by Oleg Lyan and Vincent Monet,

6. Klaipeda, 2013.

7. Master thesis on "Design and Construction of a Permanent Magnet Synchronous Motor" by Miss Sisuda Chaithongsuk, king mongkut's institute of north Bangkok, 2006.

8. IEEE paper on the design of pmsm rotor with ferrite magnets to substitute rare earth permanent magnets system by Aryanti Kusuma Putri, Martin Nell, Marco Hombitzer, David Franck and Kay Hameyer, 978-1-5386-2477$7 / 18$.

9. Design and control of a PMSM drive for hybrid electrical vehicle by R. Carlson, F. Wurtz, H. Voltolini.

10. IEEE paper on Permanent magnet synchronous motor magnet design with skewing for torque ripple and cogging torque reduction by R. Islam, I. Husain, A. Fardoun and K. Mclaughlin, 0197-2618/07.

11. Journal of electrical engineering paper on effects of rotor skew angle on flux switching permanent magnet (FPSM) machine characteristic by Mostafa, Seyyed Mehdi and Fabrizio. 